IR-07-026

\title{
Future Ageing in Southeast Asia: Demographic Trends, Human Capital and Health Status
}

Wolfgang Lutz (lutz@iiasa.ac.at)

Samir K.C. (kc@iiasa.ac.at)

Hafiz T.A. Khan (hafiz.khan@ageing.ox.ac.uk)

Sergei Scherbov (scherbov@iiasa.ac.at)

George W. Leeson (george.leeson@ageing.ox.ac.uk)

Approved by

Leen Hordijk

Director

September 27, 2007

Interim Reports on work of the International Institute for Applied Systems Analysis receive only limited review. Views or opinions expressed herein do not necessarily represent those of the Institute, its National Member Organizations, or other organizations supporting the work. 


\section{Contents}

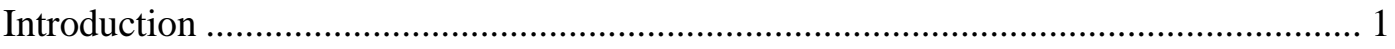

Probabilistic Population Projections for Southeast Asia and Singapore ......................... 1

Growing Human Capital: The Dynamics of the Changing Educational Composition by

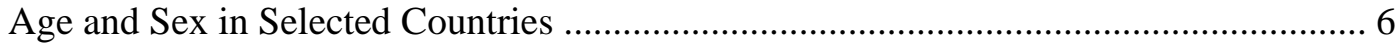

Age-Specific Patterns of Disability by Level of Education ........................................ 10

Future Trends in Disability with and without the Consideration of Improving

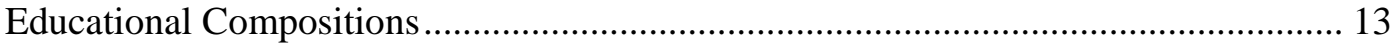

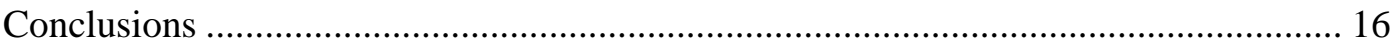

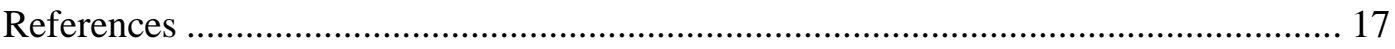




\begin{abstract}
This paper will discuss the likely changes in the composition of the population by age, sex, level of education, and health status for the whole region of Southeast Asia over the coming decades, and will show specific projections for Singapore, Malaysia, Indonesia, and Thailand. The future population trends will depend on future trends in fertility, mortality, and migration. We start by presenting population projections that explicitly consider the uncertainty in all three factors. Next, we present projections that add educational attainment as a further dimension, thus providing an outlook for human capital by age and sex. Finally, we match these projections with recently collected data from the Future of Retirement, a global ageing survey carried out by the Oxford Institute of Ageing in collaboration with HSBC on health and disability indicators by age, sex, and level of education for the four countries concerned. Together, these different pieces of analysis will give us important background information about the challenges and opportunities facing these countries in terms of the financing of ageing populations.
\end{abstract}




\section{Acknowledgments}

The authors would like to thank HSBC for providing the funds to carry out the surveys on the Future for Retirement. 


\section{About the Authors}

Wolfgang Lutz is Leader of the World Population Program at IIASA, and Director of the Vienna Institute of Demography of the Austrian Academy of Sciences.

Samir K.C. is a Research Scholar at the World Population Program at IIASA.

Hafiz T.A. Khan is a HSBC Research Fellow at the Oxford Institute of Ageing, Oxford University, UK.

Sergei Scherbov is a Senior Research Scholar at the World Population Program at IIASA, and Leader of the Population Dynamics and Forecasting Research Group at the Vienna Institute of Demography of the Austrian Academy of Sciences.

George W. Leeson is Deputy Director and HSBC Senior Research Fellow at the Oxford Institute of Ageing, Oxford University, UK. 


\title{
Future Ageing in Southeast Asia: Demographic Trends, Human Capital and Health Status
}

\author{
Wolfgang Lutz, Samir K.C., Hafiz T.A. Khan, Sergei Scherbov \\ and George W. Leeson
}

\section{Introduction}

This paper will try to draw a bigger picture about the likely future changes in age distribution in the countries of Southeast Asia and some key dimensions of the expected population ageing. It will focus on the demographic core of population ageing and also cover the changing education and health distributions of the population which are key dimensions for assessing the likely implications of these trends for individual countries. We will do so not in the conventional way of presenting already existing population projections for different countries (e.g., taken from the UN population projections or national projections) but rather we will present innovative methods of population projections, such as probabilistic projections and multi-state projections, and combine them with unique new data from a global ageing survey conducted by the Oxford Institute of Ageing in collaboration with HSBC. These new data, combined with those more sophisticated projection methods, will allow us to address some of the key challenges of population ageing much more directly. We will present these analyses here for a few selected countries.

The paper will be structured in the following way: First we present some new probabilistic population projections for Southeast Asia and specifically for Singapore. While these provide a comprehensive picture of what is likely and what is uncertain in terms of future population size and structures by age and sex, the following sections of the paper also consider the changing educational structure of the population, which has major impacts ranging from effects on demographic trends themselves to effects on health and income, among others. In the remainder of the paper, we take a closer look at expected future trends in health and disability and how the explicit consideration of educational health differentials, together with a changing educational composition of the population, influence the outlook for ageing-related health concerns.

\section{Probabilistic Population Projections for Southeast Asia and Singapore}

The field of probabilistic population projections has recently seen a major upsurge because it offers several advantages to conventional population projection variants or scenarios. As compared to the traditional UN high-medium-low variants, which are only based on alternative fertility assumptions and otherwise consider identical mortality and migration assumptions, probabilistic population projections consider the full ranges of 
uncertainty in all three demographic components of change. Disregarding mortality uncertainty is particularly problematic in the context of studying population ageing, where the uncertainty about future trends in old age mortality has a major impact. Many of these issues have been discussed in a recent issue of the International Statistical Review on the topic "How to deal with uncertainty in population forecasting" (Lutz and Goldstein 2004).

The following projections for Southeast Asia as a region come from the most recent update of the IIASA world population projections which are carried out at the level of 13 world regions, while the projections for the (resident) population of Singapore have been carried out specifically for this paper. Data sources, methods used, and specific assumptions made are documented in Lutz et al. (2004) and on the IIASA website (http://www.iiasa.ac.at/Research/POP/index.html).

Figure 1 shows the uncertainty range for the total population of Southeast Asia. The differently shaded (colored) ranges give the fractiles of the uncertainty distribution that result from 1,000 independent simulations (cohort-component projections) that were carried out by combining different fertility, mortality, and migration paths drawn from the defined uncertainty distributions. While the base line for the projections is 2000, the uncertainty only starts in 2007 because up to 2006 empirical trends have been incorporated.

South-East Asia, Total Population (in millions)

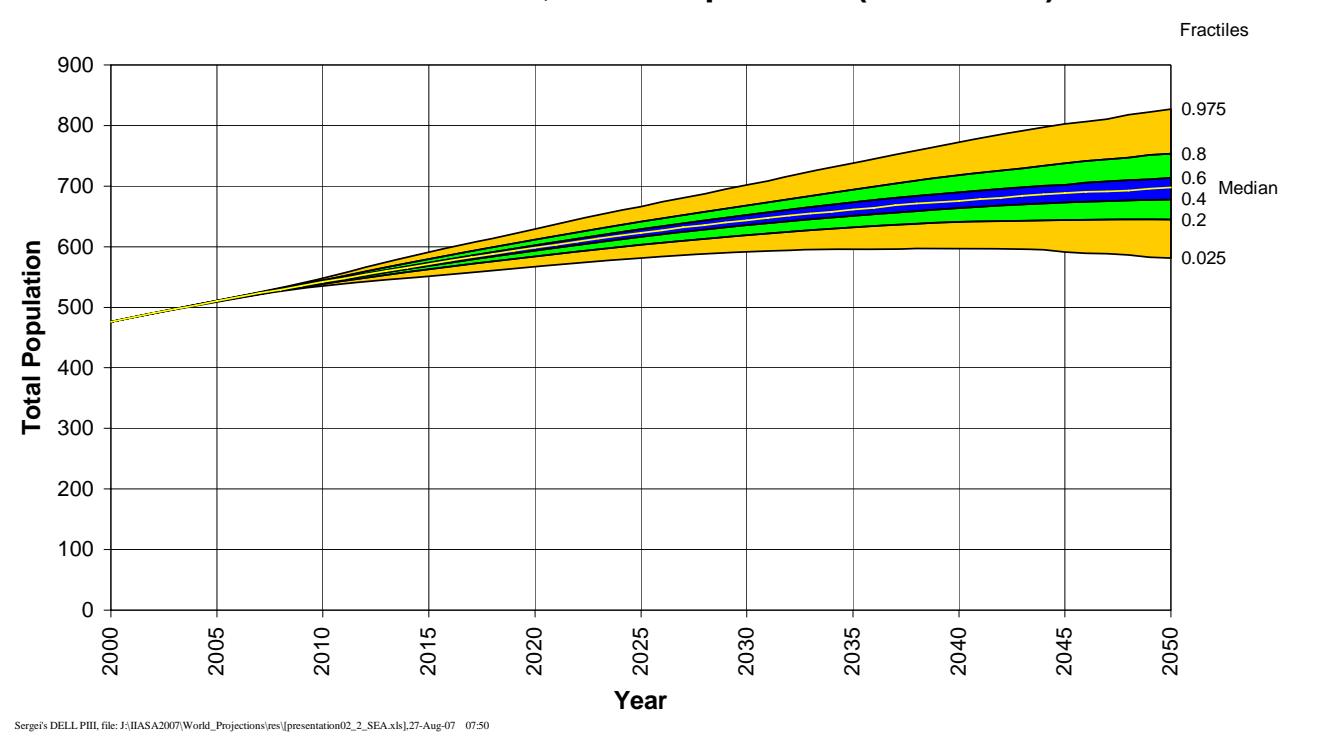

Figure 1. Uncertainty distribution for the future population size of Southeast Asia.

Figure 2 shows the uncertainty range for the total population of Singapore. For Southeast Asia as well as for Singapore by itself, the figures show that moderate future population growth is still to be expected. In Southeast Asia as a whole, this is mostly due to the momentum of population growth caused by a young population age structure 
and still moderately high fertility levels in some countries such as the Philippines; in Singapore, the expected growth is mostly due to migration gains.

\section{Singapore, Total Population}

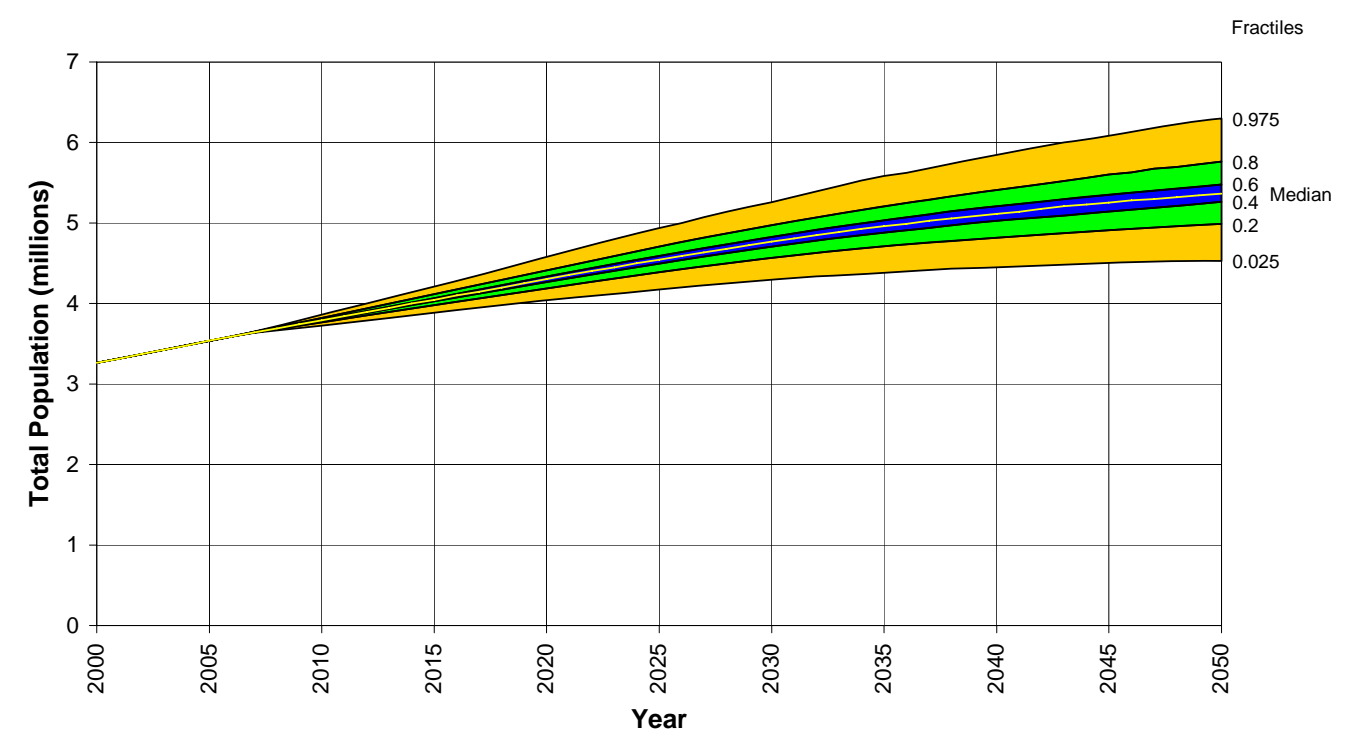

Figure 2. Uncertainty distribution for the future population size in Singapore.

Figures 3 and 4 use the same scale to make them better comparable to show the future paths in the proportion of the population above age 65, which is one of the most frequently used ageing indicators. They show that for Southeast Asia as a whole, this proportion is likely to more than triple by the middle of the century, from currently 5 percent to above 15 percent. The graph shows some uncertainty around this trend, but also that a substantial increase is a near certainty. For Singapore the current level is already higher (around 8 percent), but the increase will be even steeper with the proportion expected to reach around 30 percent by the middle of the century. While there is some uncertainty about where exactly it will lie in the range between 25 to 35 percent, there is again no doubt that it will increase to above 25 percent of the total population above the age of 65 .

Another important indicator in the context of ageing is the proportion of the population above the age of 80 , an issue that is very relevant for future health and care service provision (see Figures 5 and 6). While in Southeast Asia as a whole this proportion is only expected to increase from around one percent to three percent, Singapore shows a very different picture. Currently only two percent of the population are above age 80 , but by the middle of the century, this proportion will likely increase by a factor of six or more to around 13 percent. Depending on future migration, fertility, and mortality rates, this proportion may turn out to be a bit higher or lower, but an increase to at least 9-10 percent seems to be a near certainty. This trend poses major challenges from financial to health and pension policy considerations. 


\section{South-East Asia, Proportion above age 65}

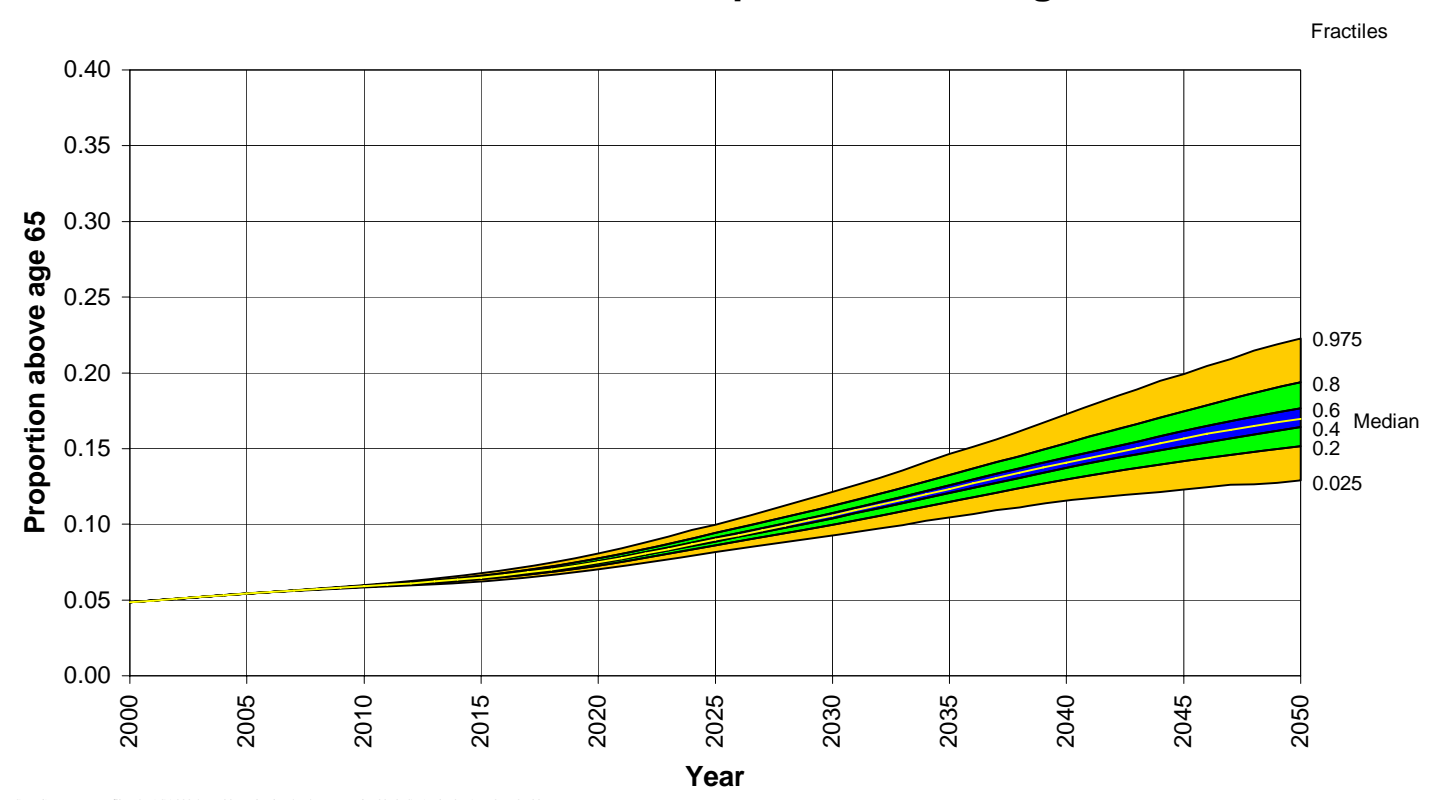

Figure 3. Future paths in the proportion of the population above age 65 in Southeast Asia.

\section{Singapore, Proportion above age 65}

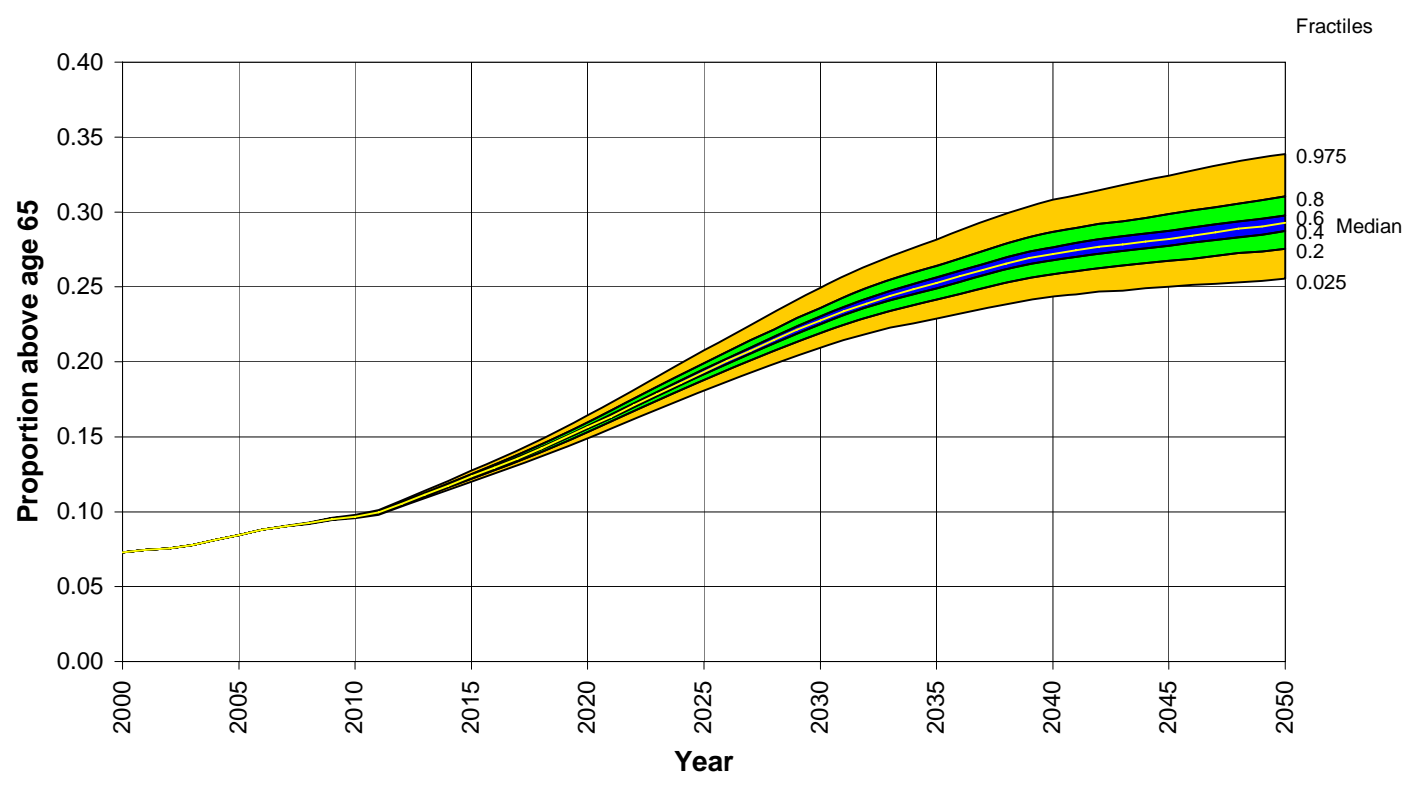

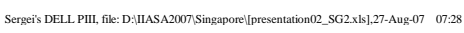

Figure 4. Future paths in the proportion of the population above age 65 in Singapore. 


\section{South-East Asia, Proportion above age 80}

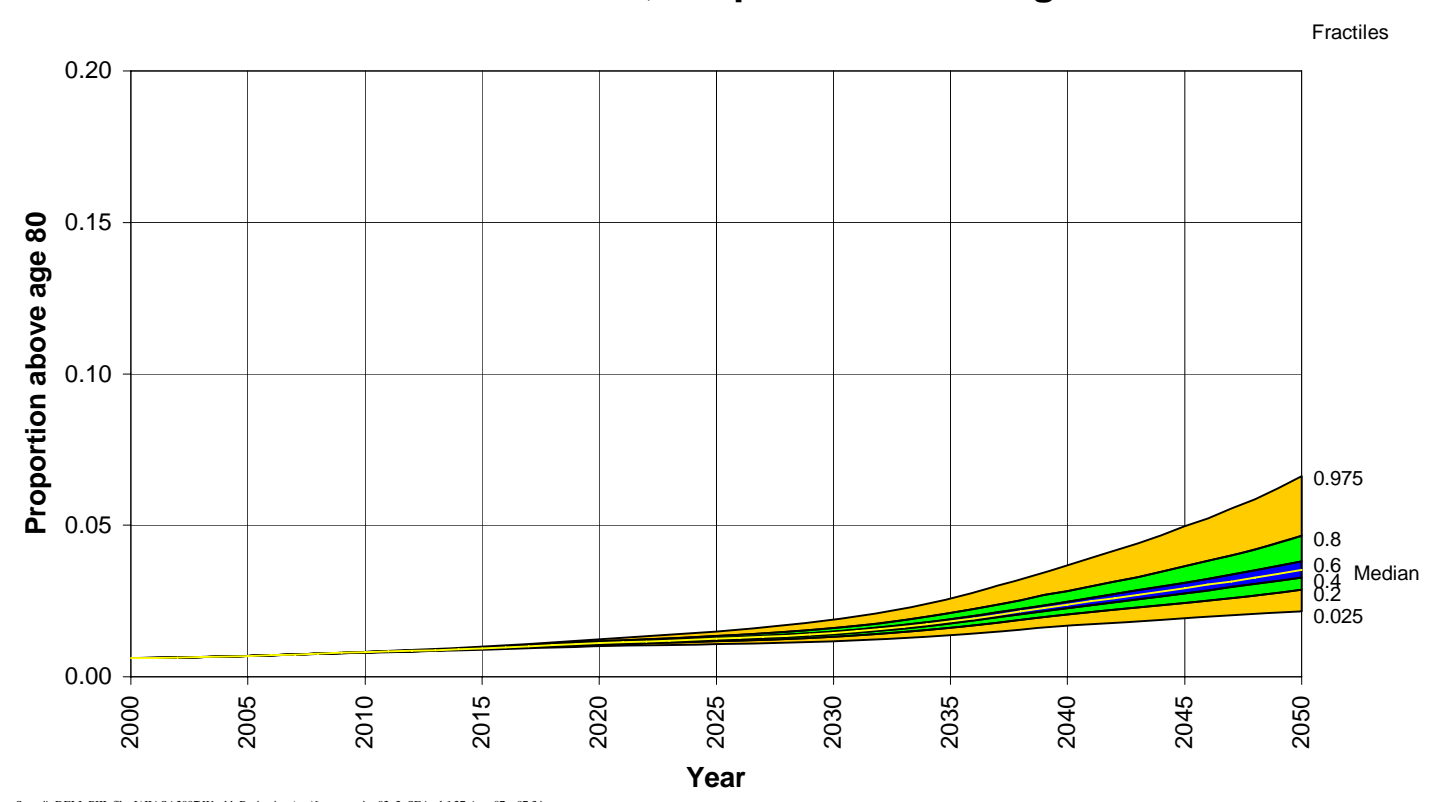

Figure 5. Future paths in the proportion of the population above age 80 in Southeast Asia.

\section{Singapore, Proportion above age 80}

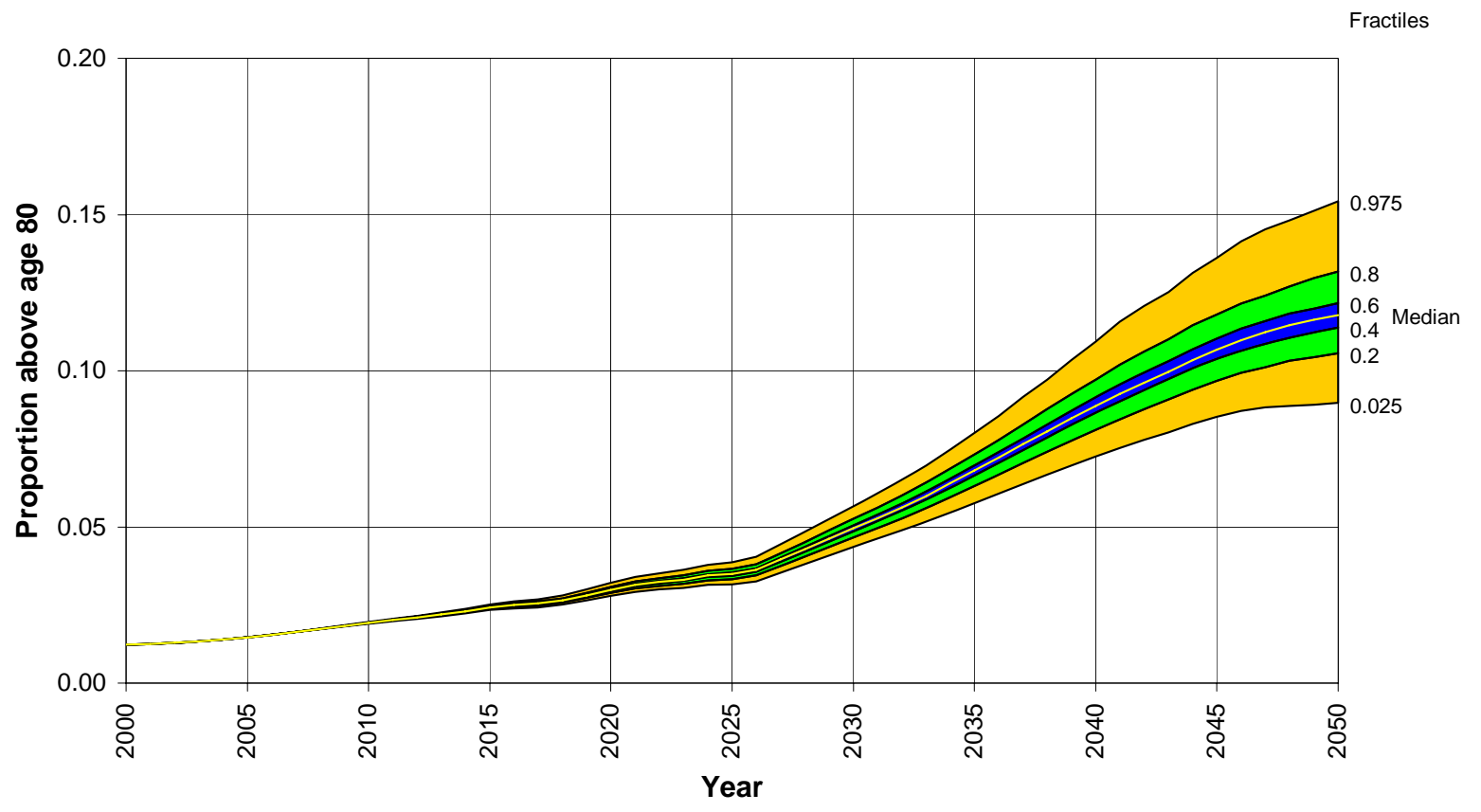

Sergei's DELL PIII, file: D:IIIASA2007_Singaporel[presentation02_SG2.x1s],27-Aug-07 $07: 34$

Figure 6. Future paths in the proportion of the population above age 80 in Singapore. 


\section{Growing Human Capital: The Dynamics of the Changing Educational Composition by Age and Sex in Selected Countries}

We know that the age and sex structure of the population is not the only relevant source of population heterogeneity when it comes to anticipating the future consequences of population ageing. Many studies have shown that the structure of educational attainment of a population matters greatly and presents a good indicator for the more difficult to measure social and economic stratification of the population. Almost universally, people with better education have better health and higher incomes. In comparison to directly considering the income distribution, educational attainment indicators have the advantage of being directly observable for each individual (need not be indirectly inferred through indicators of household income or wealth as is done for individual income) and being very stable over time (if a person has completed tertiary education, he/she will maintain in this status for life). Because of this stability and the strong relationship between education and health, the World Health Organization uses education as part of the formula for forecasting health (Mathers and Loncar 2006).

IIASA has recently conducted the first systematic projections and reconstructions of populations by age, sex, and four levels of educational attainment for 120 countries. This exercise has been extensively described elsewhere; there is no space here to give any detail about the methodology and specific assumptions. It shall suffice to say that it is based on the multi-state population projection model which simultaneously projects several populations which have different patterns of fertility, mortality, and migration rates, and also considers age- and sex-specific transitions from one sub-population to another. In the case of education projections, the sub-populations are defined by educational attainment categories (no formal education, primary, secondary, and tertiary education).

Figure 7 shows the educational attainment distribution for Singapore in 2000. The figure also includes a lot of information about the history of the education system in Singapore. Because formal education is typically acquired at a younger age and hardly changes over the life course, we see that among the women above age 60 today, still more than half have not received any formal education, although for the younger ages, Singapore has one of the most educated populations in the world. This reflects the great momentum of changing the educational attainment composition of the adult population, if education is only received at a young age. This inertia of change is also the basis for our reconstruction model of educational attainment to 1970. Put in a simple way: Those who, in 2000, were without formal education in the age group 60-64 were like that in the age group 30-34 in 1970. In order to be more precise in this reconstruction, we have to consider the facts that mortality differs with education (some of the uneducated people may have died over the past 30 years because of their higher than average mortality rates) and that migration flows can differ by level of education. IIASA has recently produced such reconstructions based on demographic back-projection techniques for 120 countries, starting with an empirical distribution by age, sex, and level of educational attainment in 2000 (Lutz et al. 2007).

This stability of educational attainment along cohort lines can also be exploited to make projections of the population by educational attainment. In this case one has to consider the fact that not only mortality and migration are education specific, but also fertility tends to vary strongly by level of a mother's educational attainment. Figures 8- 
12 show some reconstructed and projected age pyramids for the population of Singapore and for selected other Southeast Asian countries for 1970, 2000, and 2030. Because we were mostly interested in the labor force and the economic returns to education, the reconstruction was done only for the age-groups 15-64. The projections are being done for the entire population, but an educational structure is only shown from age 15 onwards.

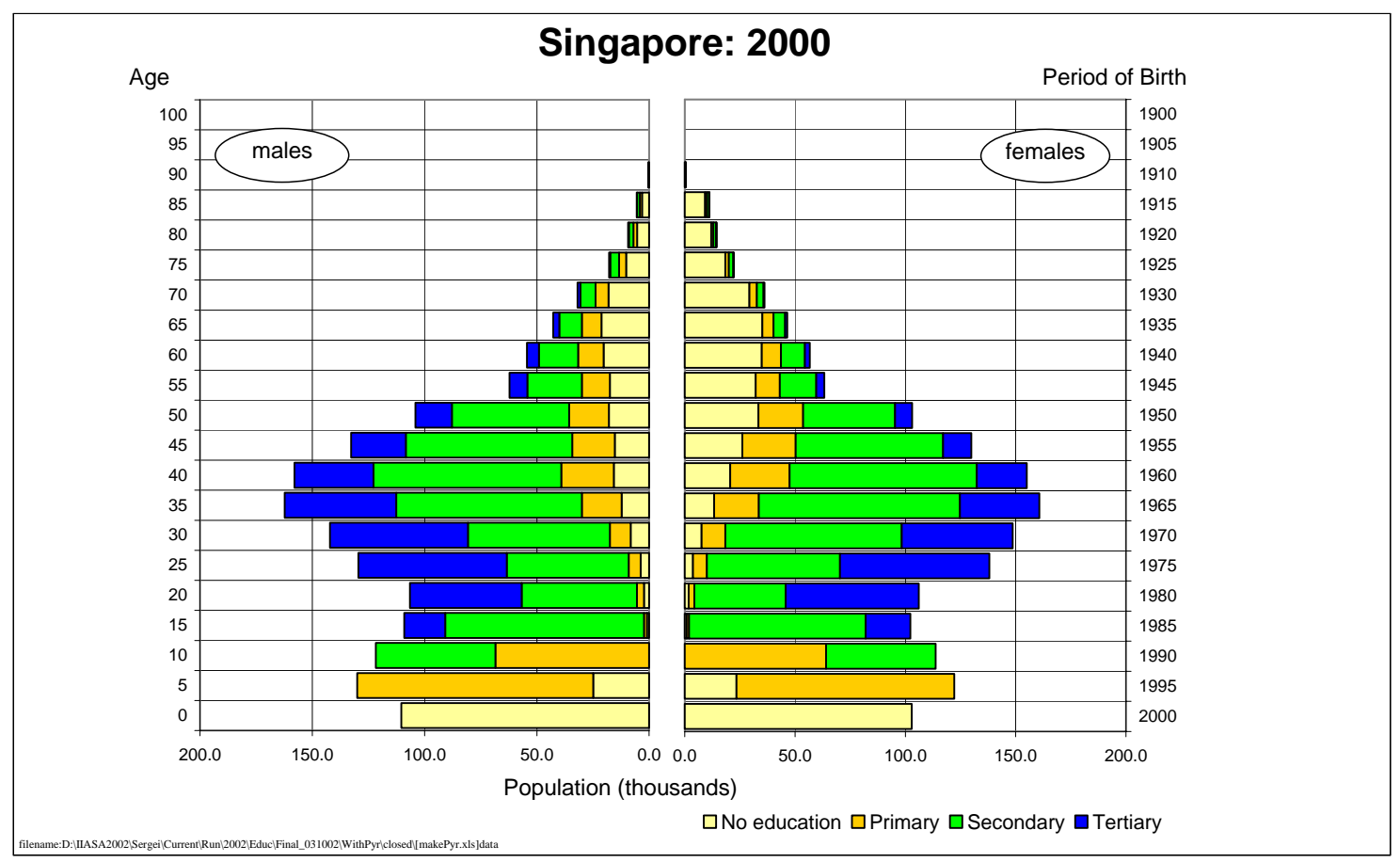

Figure 7. Age pyramid by level of educational attainment, Singapore 2000.

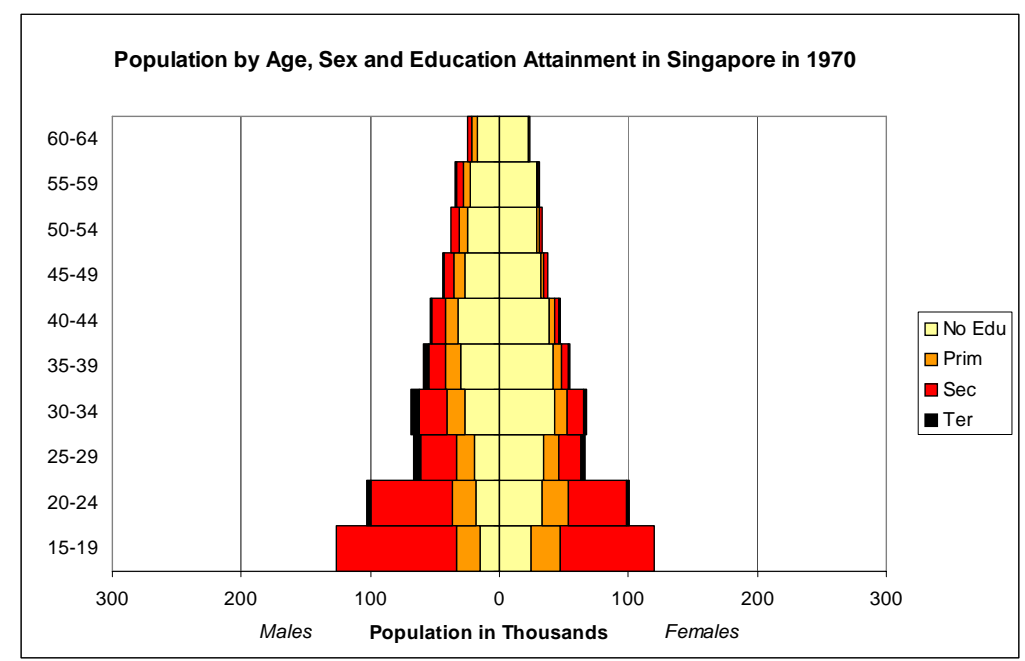

Figure 8. Reconstructions for Singapore in 1970. 


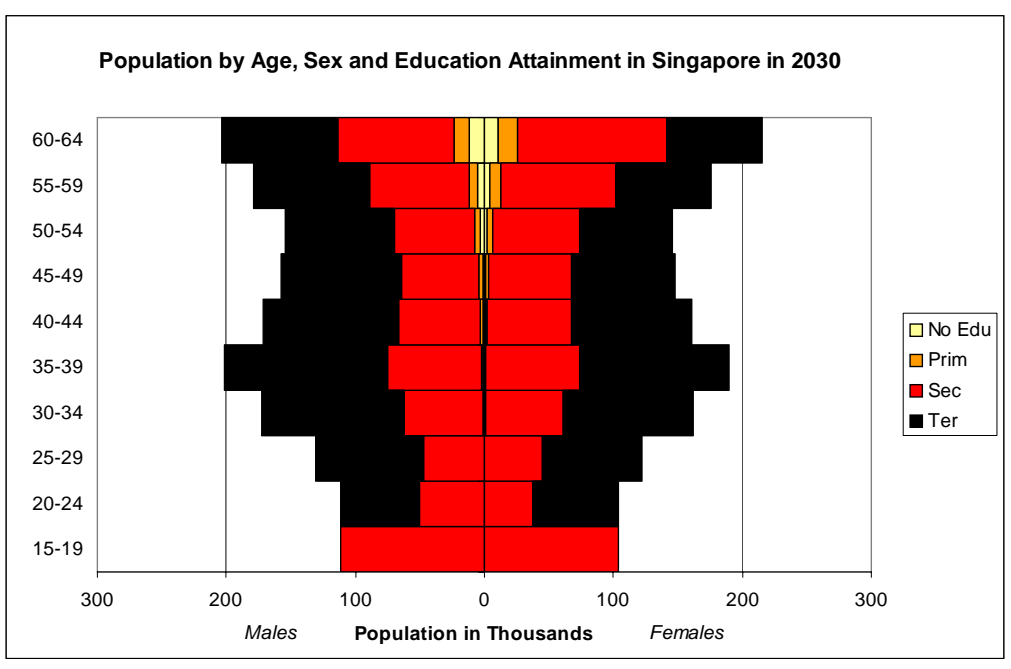

Figure 9. Projections for Singapore in 2030.

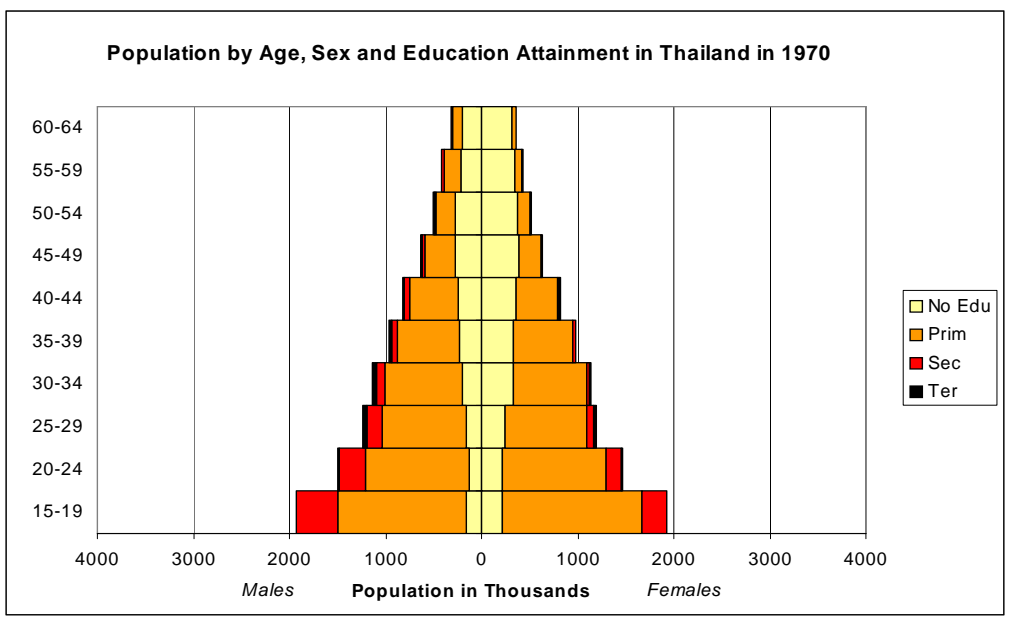

Figure 10. Age and education pyramids for Thailand in 1970. 


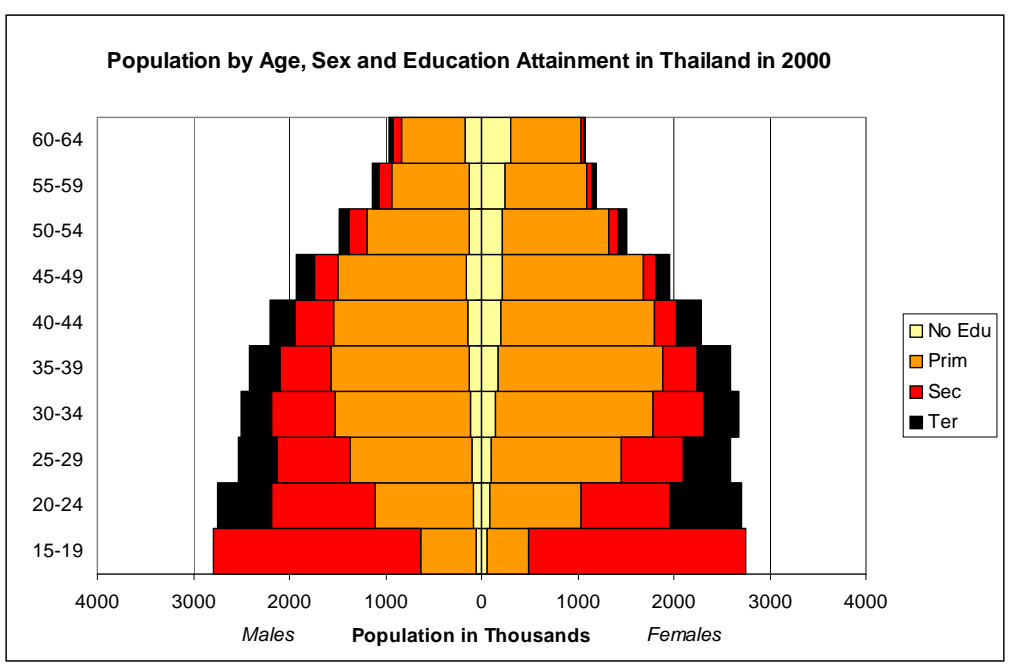

Figure 11. Age and education pyramids for Thailand in 2000.

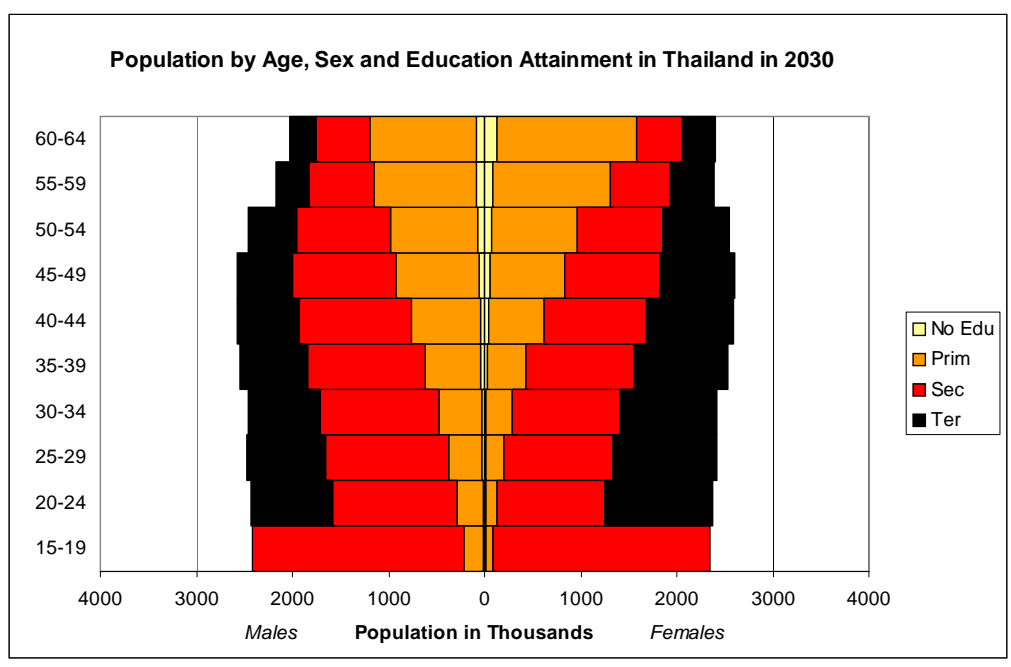

Figure 12. Age and education pyramids for Thailand in 2030.

These reconstructed and projected educational attainment distributions clearly illustrate the great momentum of improvements in the educational structure. But they also give a rather comprehensive image of the state of social and economic development in general. Figure 8, which is comparable to some African countries today, reminds us that not too long ago, Singapore was a poor developing country with a very poorly educated population, although by 1970 the first effects of the massive educational efforts were already visible among the younger generation. The projections to 2030 show that in Singapore as well as in Thailand, these educational efforts will have resulted in very highly-educated populations. This high level of human capital will likely be reflected in high economic and health standing. 
But will population ageing pose a serious threat to this anticipated high level of future wellbeing? In the following sections we will explore these questions at least with respect to health and disability.

\section{Age-Specific Patterns of Disability by Level of Education}

In the following section we will try to match some of these projections with information about the age-specific patterns of disability. The empirical basis for the latter is an international ageing survey carried out by the Oxford Institute of Ageing together with the HSBC (The Future of Retirement). The study utilizes data collected in the study of the Future of Retirement, a global, cross-sectional ageing survey conducted in 21 countries and territories in 2006 by Harris Interactive Inc. (a worldwide market research firm; for more information, see www.harrisinterative.com) under the auspices of HSBC. The principal aim of the survey has been to investigate people's attitudes towards health and retirement, and to draw general conclusions for the wellbeing of the elderly. A total of 21,233 respondents aged 40-79 years were successfully interviewed from all five major regions of the world: Asia, Europe, North America, Latin America, and Middle East/Africa. The countries which took part in the survey are listed as China, Hong Kong, India, South Korea, Japan, Malaysia, Singapore, Philippines, Taiwan, the United Kingdom, Germany, Russia, France, Denmark, Canada, the United States, Brazil, Mexico, Saudi Arabia, Turkey, and South Africa. The interviews were mostly conducted by telephone and on some occasions face to face. The whole data collection, editing, coding, and final data entry were done by Harris Interactive. Individuals were drawn from various social classes with a proportional representation of age and sex. The questionnaires contained a wide range of questions about respondents' sociodemographics and other attitudes, policies, and practices towards older people. Individuals were asked a battery of structured questions regarding their attitudes and perceptions to employment and retirement. Among much other information, this survey also contains self-reported information about disabilities measured through the familiar ADL (activities of daily life) scheme. The ADL score used in this analysis gives the average number of activities of daily life (taken from a standard list) for which the respondents report difficulties. This average score is calculated for five-year age groups as well as for age groups by four levels of education.

Since the sample sizes in the survey are too small to get stable patterns for disabilities of very specific sub-populations (such as those with tertiary education in a specific five-year age group), the calculations below are, in certain instances, based on a pooled age and education profile that results from combining the patterns from the four countries considered.

Figures 13-16 clearly show the expected pattern with the ADL score increasing strongly with age. While women aged 40-49 have almost the same low ADL scores as men of the same age, the speed of increase with age is much more pronounced for women than for men. By age group 70-79, women (in most countries around the world) report significantly higher levels of ADL problems than men of the same age. There are

also interesting differences among countries, with Singapore being at the lower end of the age-specific disability rates. 


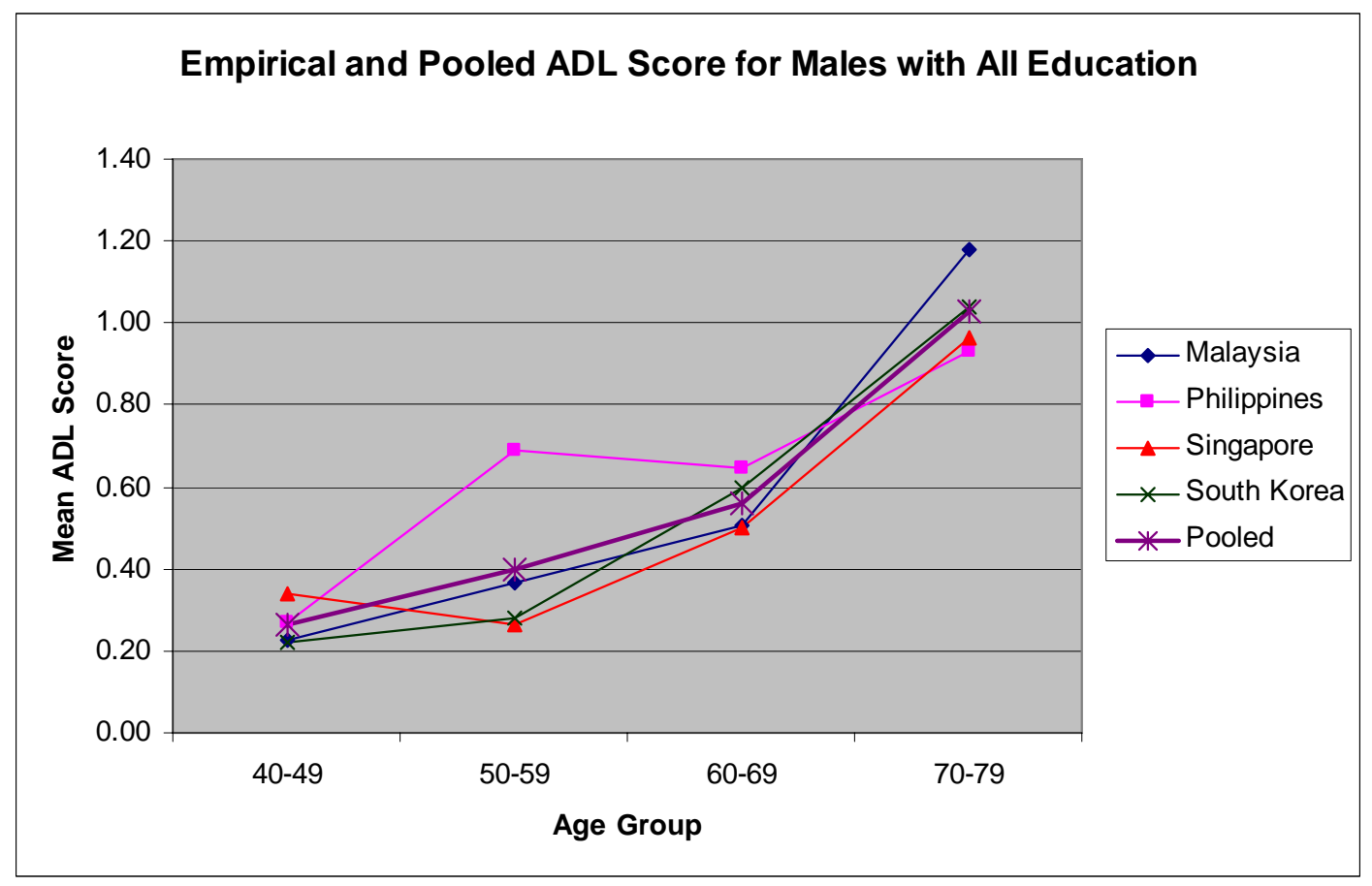

Figure 13. Age profiles of ADL scores (average numbers of activities of daily life for which a person has problems) for Malaysia, the Philippines, Singapore, and South Korea, as well as a pooled profile for men (all educational levels combined).

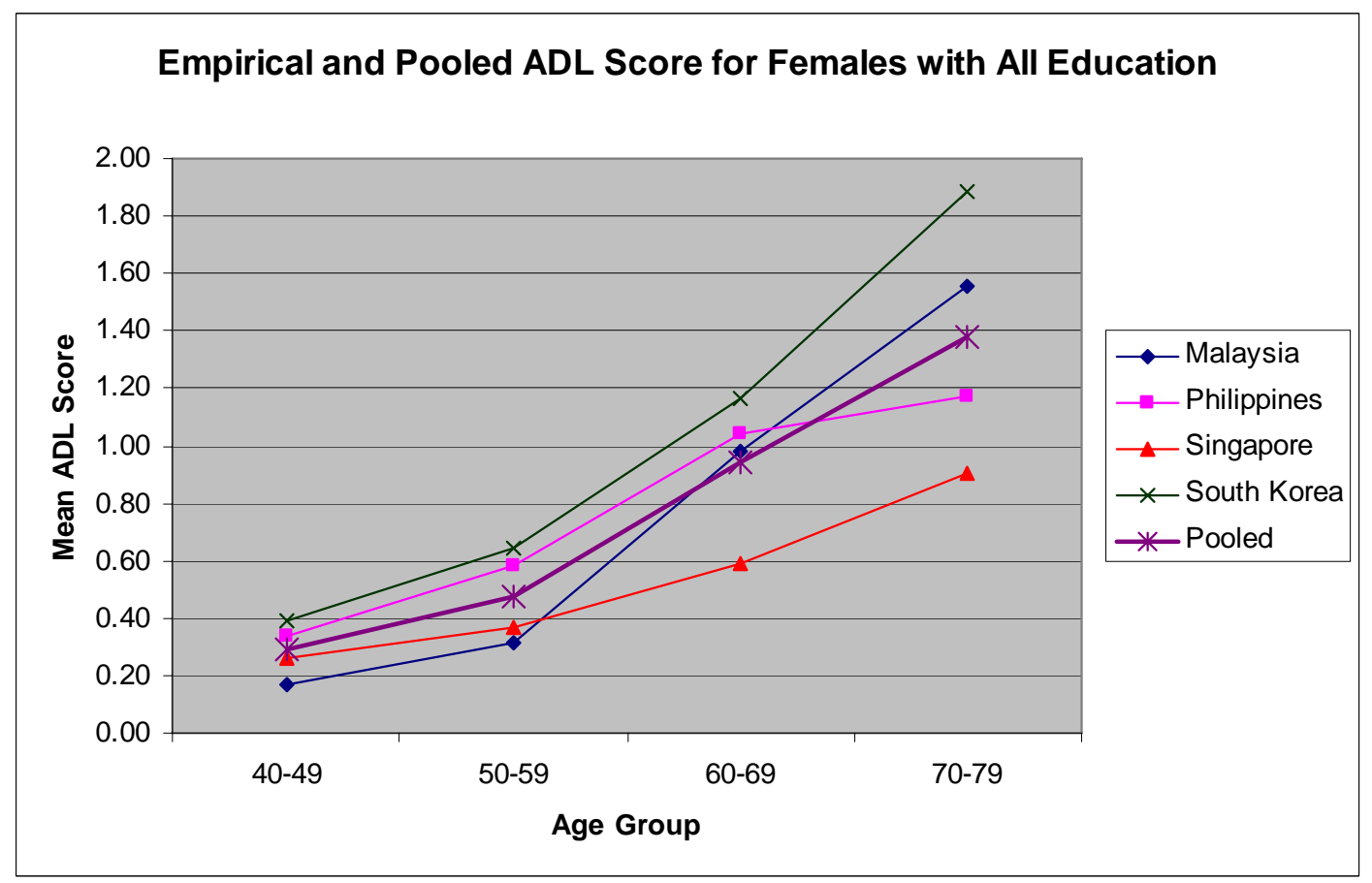

Figure 14. Age profiles of ADL scores (average numbers of activities of daily life for which a person has problems) for Malaysia, the Philippines, Singapore, and South Korea, as well as a pooled profile for women (all educational levels combined). 


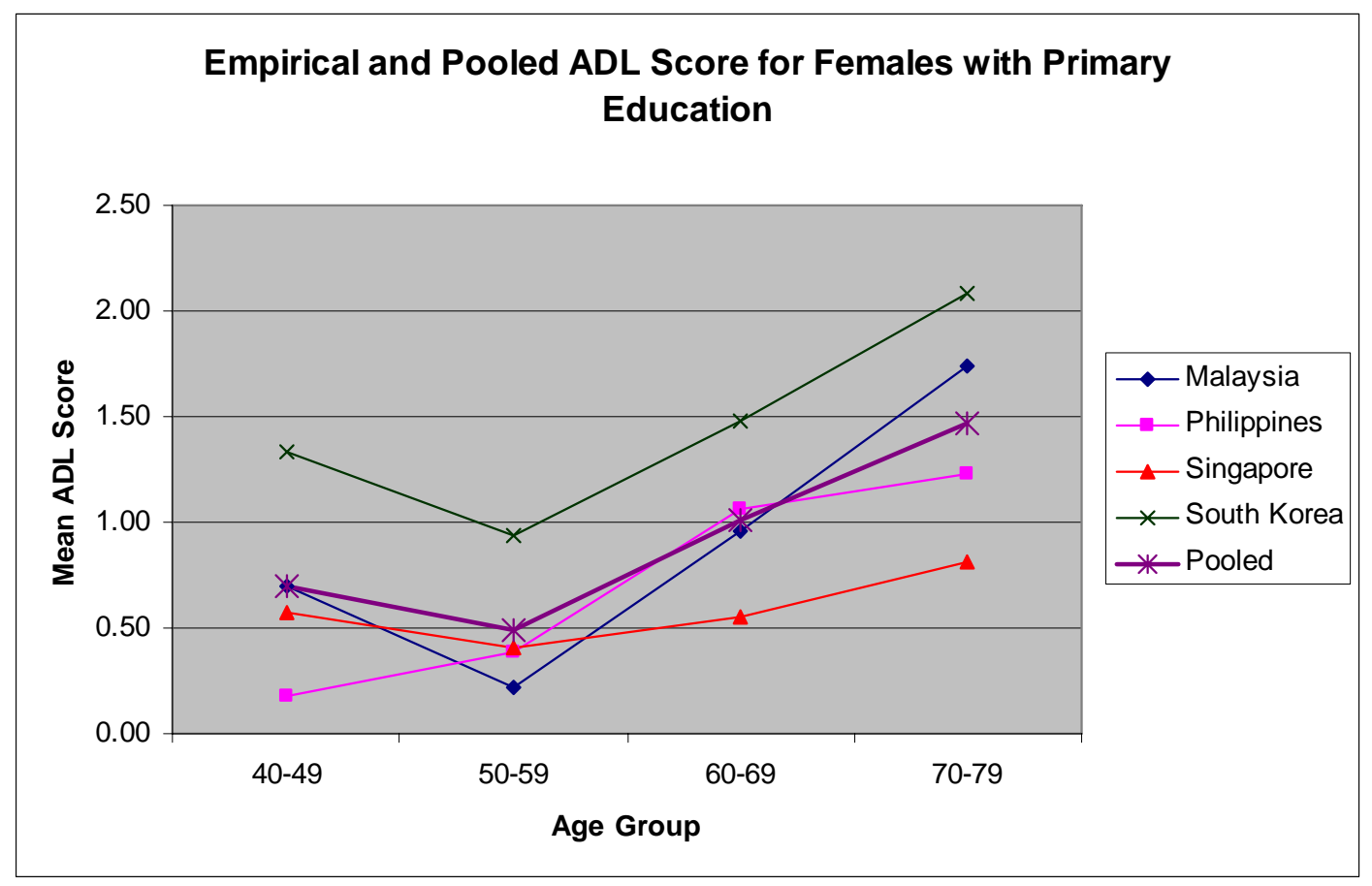

Figure 15. Age patterns of ADL scores for women with primary education only.

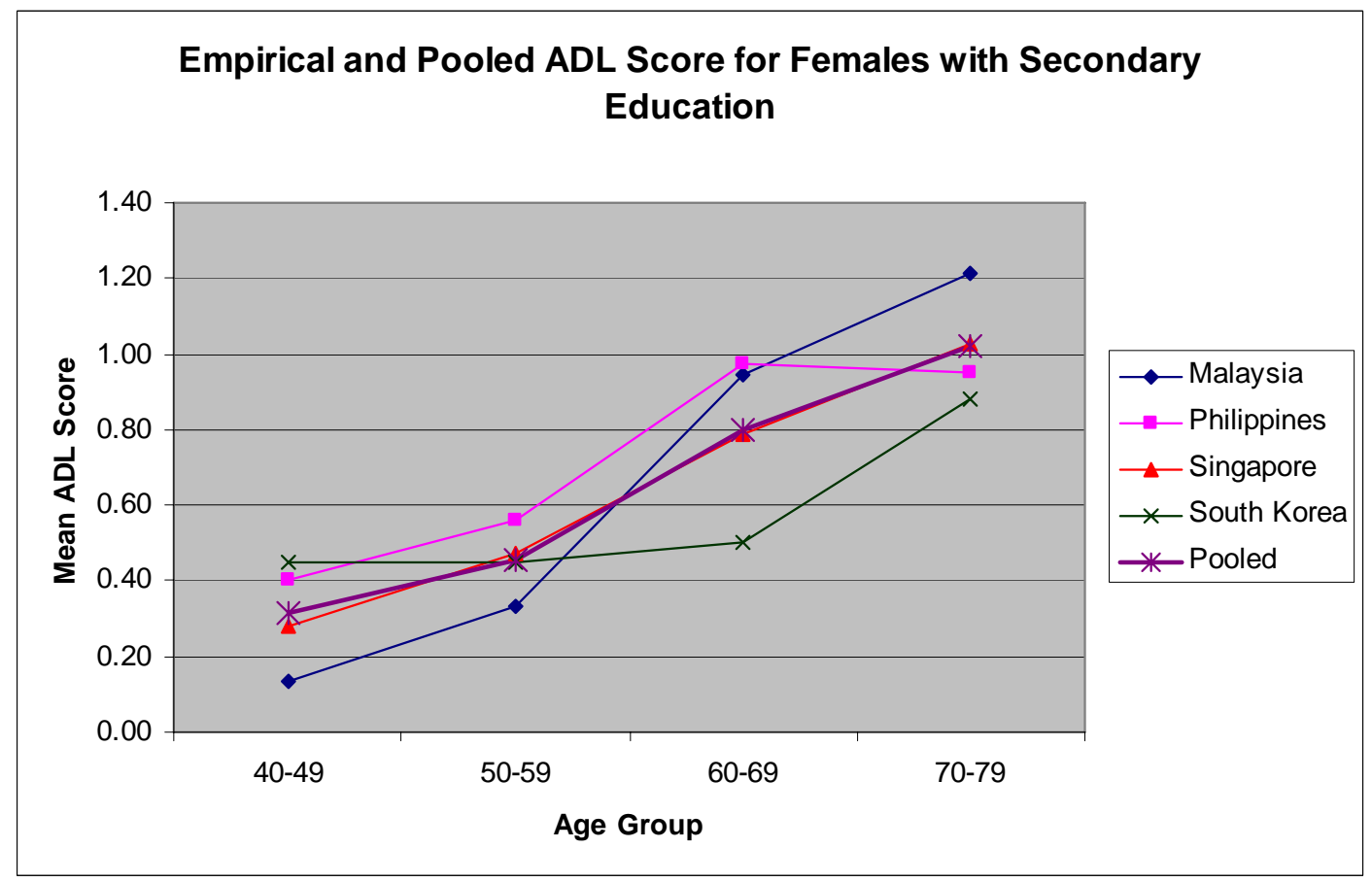

Figure 16. Age patterns of ADL scores for women with secondary education as their highest attainment. 
Figures 15 and 16 clearly show a consistent pattern of the more highly educated women having lower disability rates than less educated women. This difference is particularly strong in South Korea. The patterns of increase with age tend to vary with the level of education. For women with secondary education, the increase is more linear; for less educated women in three of the four countries, the ADL score is higher in the age group 40-49 than for those aged 50-59 before resuming a steep increase. This interesting pattern would deserve some deeper analysis.

\section{Future Trends in Disability with and without the Consideration of Improving Educational Compositions}

In this section we will present some calculations about the possible impact of an improving educational composition of the population on future health and disability. Many of the pessimistic outlooks that have been presented in Europe and increasingly in ageing Asian countries are based on a somewhat simplistic rationale, namely, applying the age pattern of disability of today to the population age structure of the future. Given the steep age gradient of disability observed, e.g., in the figures above, it is no wonder that applying them to an older age structure will result in much higher disability rates. However, Lutz and Scherbov (2005) have recently shown for the European Union that if this age pattern of disability is slightly moved to the right by two years per decade (i.e., in the future the same disability prevalence will apply to an age group two years older), then even the massive ageing of the baby boom in Europe will not result in any longterm increase in the proportions of people with disabilities. Hence, likely future declines in age-specific disability rates can mitigate most of the ageing effect.

In the Asian context, Hermalin et al. (2006) suggested that the fact that younger cohorts tend to be better educated is expected to lead to lower mortality and morbidity rates for given age groups in the future. In the following, we will present a more formal analysis of this question, comparing projections that are based on a constant ADL age profile to ones that explicitly consider educational differentials in ADL, as well as the projected future educational attainment distributions.

Figures 17-20 present projections of the average ADL scores for the four countries considered by simply applying the empirical age patterns described above to the projected age structures. Because we do not have empirical information on the disabilities of the population below age 40, for these simple calculations we assumed that it is constant at the level of 0.1 for all age groups below 40. The results for all countries indeed show a significant increase in the average ADL score within the population aged 15-79. The specific pattern of this increase for each country depends on the specific age profiles and country-specific paths of ageing. Also note that these calculations do not include information on the rapidly growing age group 80+ which will also have the highest ADL scores. The reason is that we do not have any empirical information on this age group.

For this same reason (lack of empirical information), the following analysis will be limited to ageing within the range of 40-79. Because ageing within this specific age band is going to be much less significant than ageing at the level of the full population, the increases in ADL scores over time tend to be much lower. But it will be sufficient to illustrate the point that we want to make. 


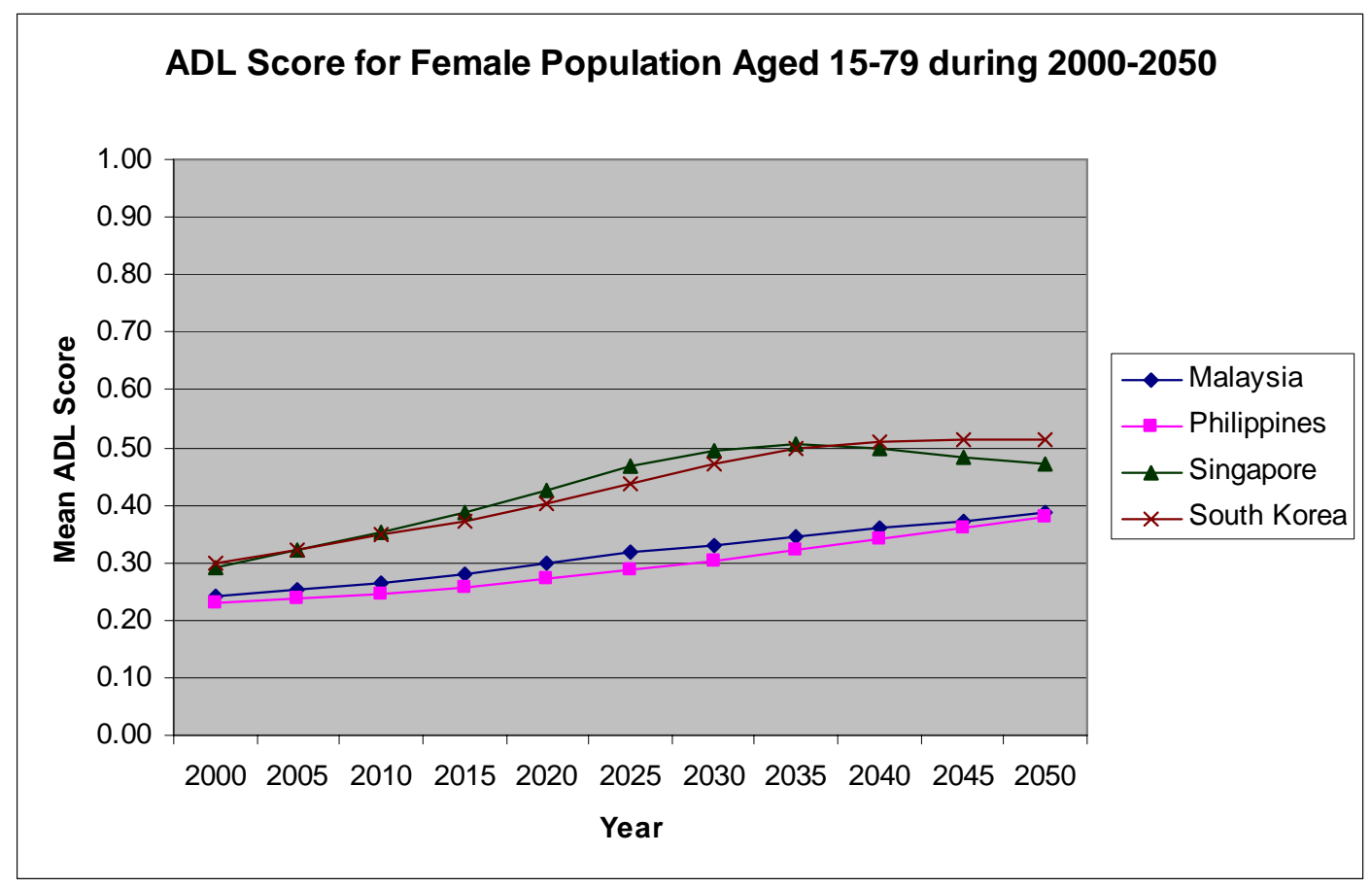

Figure 17. Increases in the average ADL score of the female population aged 15-79 to 2050, not considering the changing educational composition of the population.

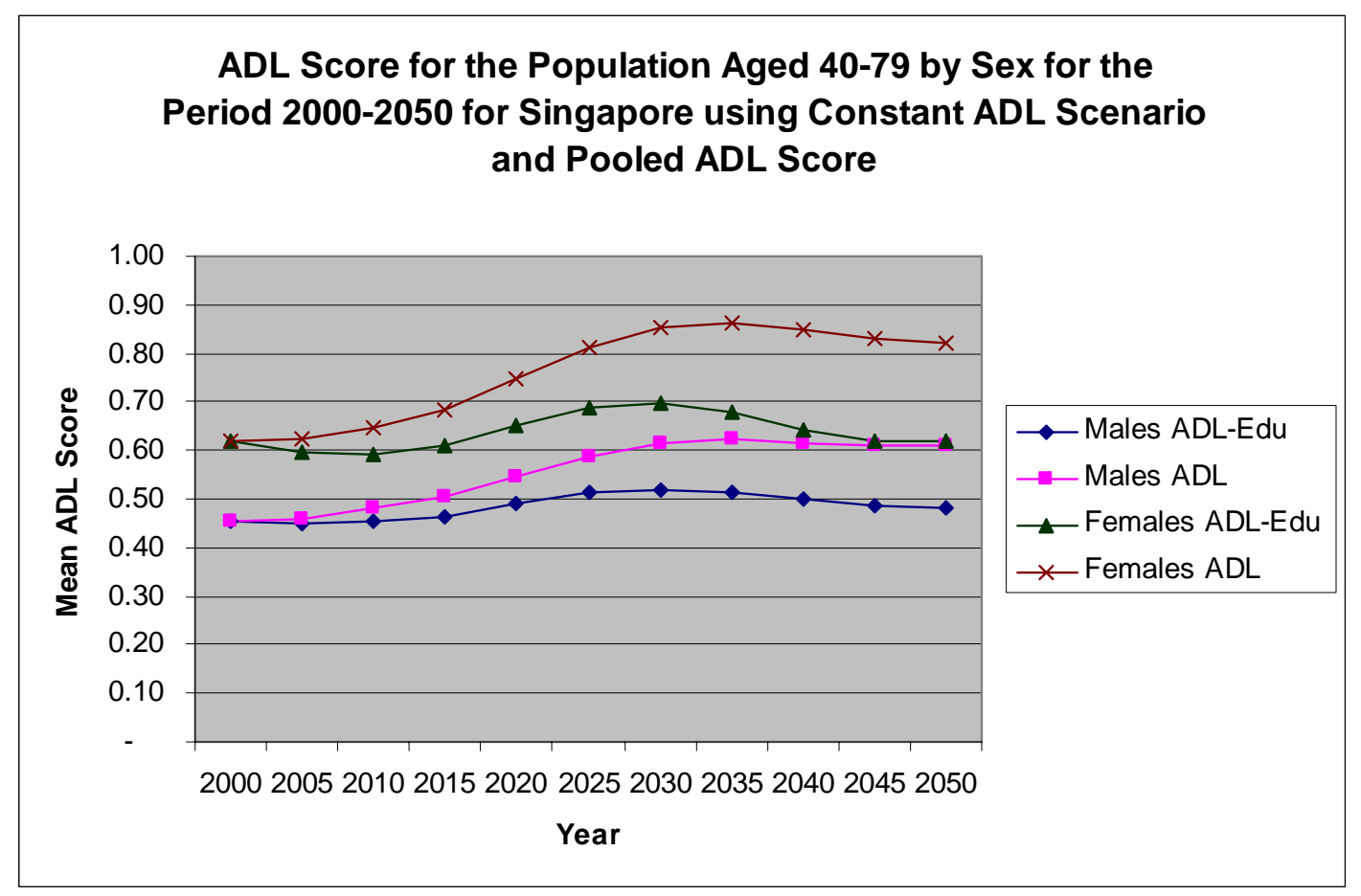

Figure 18. Increase in the average ADL score for men and women for Singapore up to 2050 under two scenarios: 1) considering the changing educational and age structure of the population (“ADL-Edu”), and 2) only considering the changing age structure (“ADL”). 


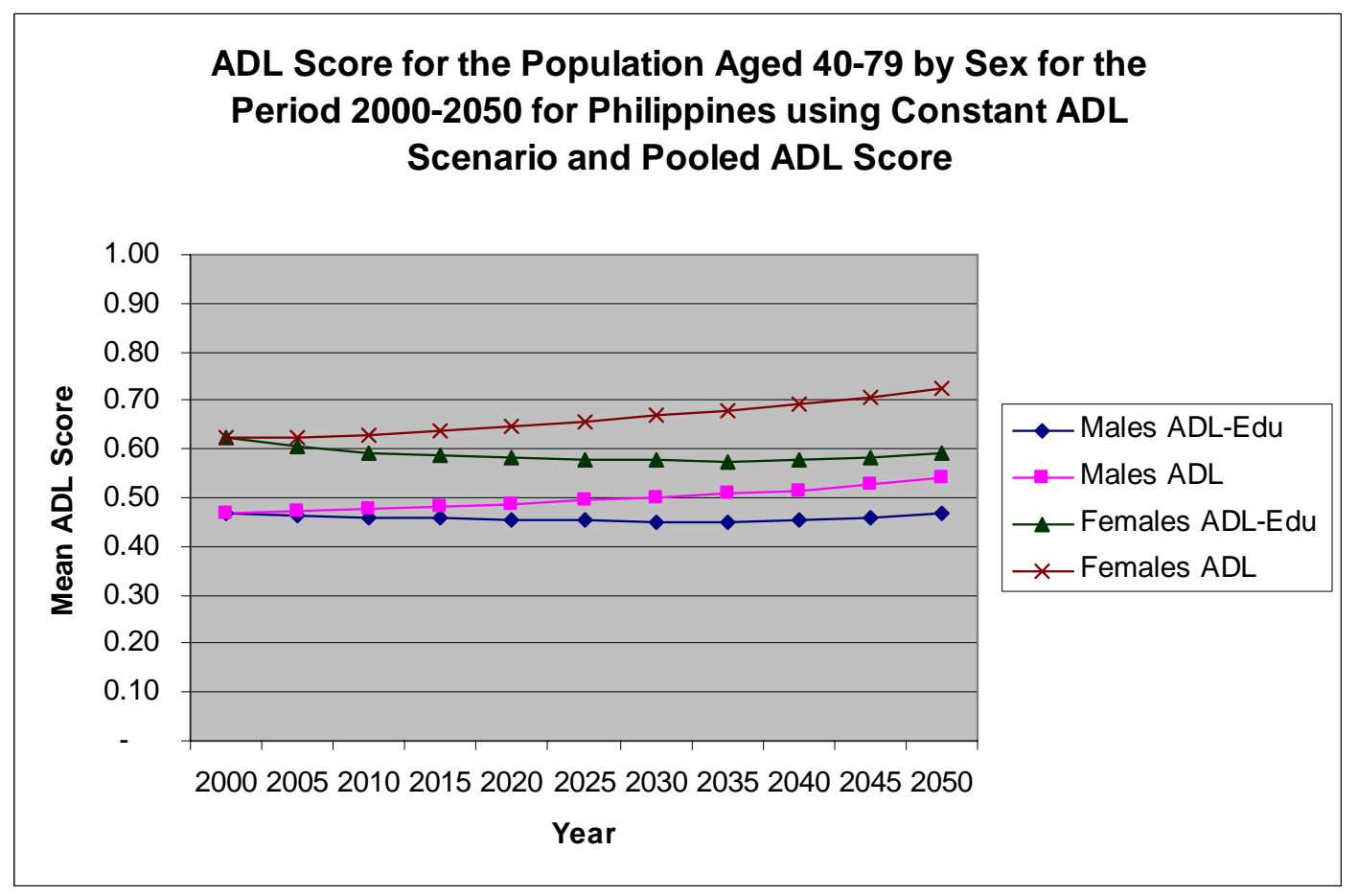

Figure 19. Increase in the average ADL score for men and women for the Philippines up to 2050 under two scenarios: 1) considering the changing educational and age structure of the population (“ADL-Edu”), and 2) only considering the changing age structure (“ADL”).

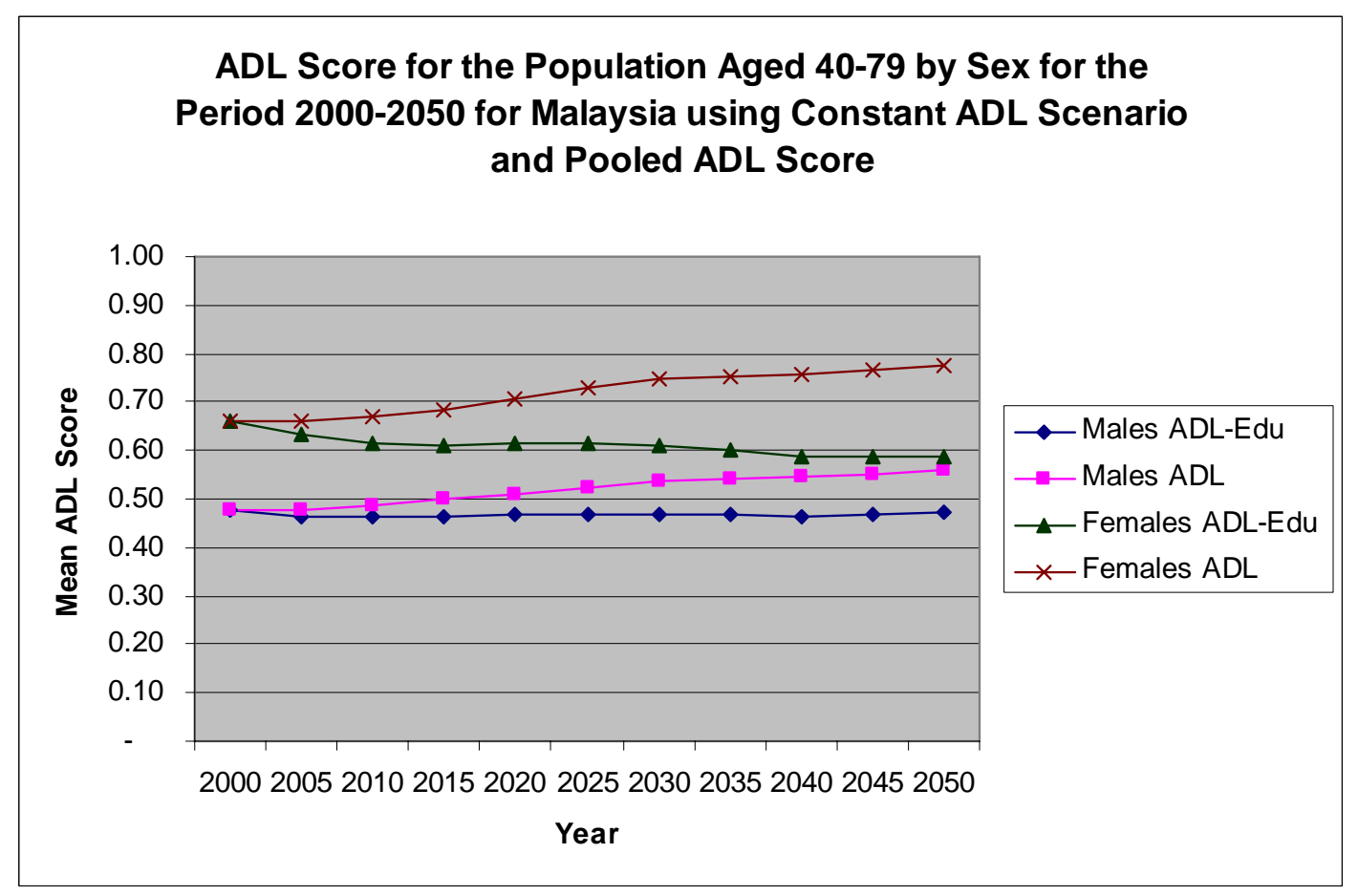

Figure 20. Increase in the average ADL score for men and women for Malaysia up to 2050 under two scenarios: 1) considering the changing educational and age structure of the population (“ADL-Edu”), and 2) only considering the changing age structure (“ADL”). 
These calculations show very clearly that the already pre-programmed improvement of the educational composition of the population has a great impact on the future prevalence of disability in the population. In all countries considered and for both men and women, the average ADL would increase if only the changing age structure of the population would be considered. And in all cases, the explicit consideration of the changing educational composition makes this increase disappear or even lead to a decrease in the future ADL score.

As discussed above, due to data limitations we could only compare the trends for ageing within the age range 40-79. But there is no reason to assume that a similar exercise carried out for the entire age range would yield qualitatively different results. Hence, these calculations impressively show that the future improvement in the educational composition of the population, that is mostly a consequence of past efforts in educating the young, will likely have a beneficial effect on ameliorating some of the feared consequences of future population ageing.

\section{Conclusions}

Over the coming decades, Southeast Asia is likely to experience moderate population growth combined with massive population ageing. The proportions of the population that will be above age 65 are likely to increase by a factor of three or more. The specific speed of this ageing wave in each country depends largely on the history of fertility decline in the country. The more rapid the fertility declined over the past decades, the steeper the increase in the proportions elderly.

But the rapid fertility declines have produced a demographic window of opportunity with periods of very low total dependency ratios (fewer children but not yet many elderly). This demographic window, sometimes called the "demographic bonus", is widely acknowledged to have contributed significantly to economic growth in the region. But the demographic window does not automatically lead to higher economic growth. The window needs to be utilized and must not be overslept. One of the most important uses of this window has been strong investments in education. Declining fertility makes it easier to rapidly increase the proportions of all children who go to school and even finish higher education. The economic bonus from lower dependency ratios makes it easier to find the resources for improving education and health care and in turn, more and better education leads to lower fertility rates further enhancing this virtuous cycle of lower fertility, better education, better health, and higher economic growth. While many countries (particularly in Africa) are suffering from these same interactions in terms of a vicious circle, where high population growth due to high fertility is combined with poor health and low education and hence, poor economic performance, most countries in Southeast Asia have managed to enter the virtuous circle. This is the basis of the often-praised Asian miracle.

Does the looming wave of population ageing, a long-term consequence of the fertility decline, now pose a serious threat to wellbeing in these countries? Again, improving human capital seems to offer a way to avoid some of the possible negative consequences associated with rapid ageing. Better-educated elderly will be in better health and will be more capable of providing for their support at old age. In this paper we have shown empirically that considering the expected improvements in the 
educational composition of the future elderly population will lead to much lower increases in disability than one could expect without improvements in education.

One can even view this as a second wave of longer-term benefits from the early investments in education in Southeast Asia. The first benefits came when the bettereducated young people entered the labor force and helped to boost economic growth. The later benefits will come when these better-educated people grow old and are in better health and economic standing because of their education. This illustrates the important returns to education and the fact that it is a long-term investment, where the benefits often only come several decades after the investment.

Even given the "education bonus", population ageing still poses many challenges for institutional adaptation, including the financing of the pension and health care system. The sooner these challenges are addressed, the easier it will be to find satisfactory solutions.

\section{References}

Hermalin, A., M.B. Ofstedal, and R. Tesfai. 2006. Future characteristics of the elderly in developing countries and their implications for policy. Asian Population Studies 3(1): 5-36.

Lutz, W. and J. Goldstein, Guest Eds. 2004. Special issue on "How to deal with uncertainty in population forecasting?” International Statistical Review 72(1\&2): 1-106, 157-208.

Lutz, W., W.C. Sanderson, and S. Scherbov, Eds. 2004. The End of World Population Growth in the $21^{\text {st }}$ Century: New Challenges for Human Capital Formation and Sustainable Development. London: Earthscan.

Lutz, W. and S. Scherbov. 2005. Will population ageing necessarily lead to an increase in the number of persons with disabilities? Alternative scenarios for the European Union. Pages 219-234 in W. Lutz and G. Feichtinger (eds.), Vienna Yearbook of Population Research 2005. Vienna, Austria: Verlag der Österreichischen Akademie der Wissenschaften.

Lutz, W., A. Goujon, S. K.C., and W. Sanderson. 2007. Reconstruction of Populations by Age, Sex and Level of Educational Attainment for 120 Countries for 19702000. Interim Report IR-07-002. Laxenburg, Austria: International Institute for Applied Systems Analysis.

Mathers, C. and D. Loncar. 2006. Updated projections of global mortality and burden of disease, 2002-2030: Data sources, methods and results. Evidence of Information and Policy Working Paper. Geneva, Switzerland: World Health Organization. 